\title{
The Interpretations and Pedagogical Strategies of Piano Ensemble Music
}

\author{
Kuo-Ying Lee ${ }^{1, *}$ \\ ${ }^{1}$ College of Music, Zhaoqing University, Zhaoqing, Guangdong, China \\ *Corresponding author. Email: kuoyinglee@hotmail.com
}

\begin{abstract}
In performing arts, the piano ensemble literature has a wide variety of repertoire that demands versatile skills such as sight-reading, rhythmic stability, coordination and communication. Piano ensemble playing has a very different training discipline and learning process from the piano solo performance as it requests more collaborations and rehearsals. The programs for piano ensemble have both artistic and pedagogical purposes, which deserve an in-depth investigation. Most existing scholarly researches mainly address the compositions for piano duets and piano duos, as both genres domain the most majority in the piano literature. Some exceptions of studies mention the overall ensemble program for multiple pianists without specifying the artistic perspectives. However, the piano ensemble program is very diverse, and there is much more to be learned from the piano ensemble performance. In order to explore the significance of the artistry of piano ensemble music, the goal of this study is to examine the repertoire for piano ensembles with respect to its social function, stylistic change, compositional intent, and pedagogical strategies.
\end{abstract}

Keywords: Piano ensemble performance, Piano ensemble literature, Piano ensemble repertoire.

\section{INTRODUCTION}

The primary keyboard literature contains a long history of solo piano compositions and the artistic output of piano ensemble. Piano ensemble indicates how two or more pianists collaboratively play the same piece on one or more pianos. The piano ensemble's presentation spans from the piano duet, piano duo, piano for six hands, piano for eight hands, to piano for twelve hands. The piano duet concept means two pianists play on one piano, while the piano duo indicates a form in which two pianists play two pianos on the same piece. The piano ensemble has gradually evolved and changed in accord with the social and cultural developments in history. Nowadays, the piano ensemble performance is widespread in the concert event, and the popularity of piano-ensemble playing opens a new field of study in collaborative artistry that presents a broader sense of the piano program.

\section{OVERVIEW OF LITERATURE}

Current scholarly findings of the piano ensemble can be divided into four categories [1].
The first type is the researches compelling lists of duo-piano pieces. For example, James Friskin and Irwin Freundlich's book, Music for Piano: A Handbook of Concert and Teaching Material from 1580 to 1952, has the first account of original musical works written for four hands and two pianos [2]. The second type of study on piano ensemble mainly evaluates and analyzes the contemporary compositions for piano duos. Gary Keith McRoberts contributed a notable example in his 1973 thesis, "An Annotated Catalog of Original Two Piano Literature 1950-1970", which illustrates the composers, stylistic features, duration, structure, and publisher of his selected piano duos in alphabetical order [3]. Another relevant research of this type on contemporary piano ensemble works was made in 1978 by Eulalie Wilson Jeter. She made an examination of original two-piano music between 1940 and 1974 by five contemporary American composers including Aaron Copland, John Corigliano, Norman Dello Joio, Vincent Persichetti, and Alan Hovhaness [4]. The third type of researches including a manual titled Team Piano Repertoire: A Manual of Music for Multiple Players at One or More Pianos by Frederic Ming 
Chang and Albert Faurot (1976), Carolyn Maxwell's Maxwell Evaluation Notebook-Ensemble Piano Literature (1983), and Howard Fergusn's book Keyboard Duets from the $16^{\text {th }}$ to the $20^{\text {th }}$ for One and Two Pianos: An Introduction (1995). These references focus on the historical development of piano ensemble literature [5] [6] [7]. There are also some other articles on the literature of piano ensemble. A representative case study is William Crandall Leech's 1941 article, "Music for Two Pianos", concludes most aspects of piano ensemble music including repertoire list for original two keyboards or two pianos from renaissance to the $20^{\text {th }}$ century, duet playing in both the arrangement of transcription and soloaccompaniment text of two pianos, duet players groups from Bach's family to the contemporary teams such as Joseph and Rosina Lhevinne and others. Leech also discussed the duet pieces for teaching purposes in his article [8]. In 1951, Pauline Venable Turrill wrote a thesis devoted to the duet repertoire for harpsichord, clavichord, spinet, virginal, and piano [9]. Turrill's thesis, "The Two-Piano Idiom: An Analysis and Evaluation", demonstrates the expansion of piano ensemble repertoire with the historical background description that explains why the piano ensemble music continually increases. The fourth type of piano-ensemble dissertations or theses emphasizes the performing aspects of a piano ensemble. The hallmark works of this kind provide performance suggestions in terms of practice method and partnership for a specific composition or a certain period of piano-ensemble pieces, mainly for piano duos. For instance, Dorotht Bridenthal's 1945 thesis, titled "A Critical Evaluation of Two-piano Music Available in American Publication", discusses the ensemble playing of two-piano music at the time through American publisher [10]. Besides, Hans Moldenhauer's book Duo-Pianism (1950), and Clyde Duncan's 1967 article, "Teaching Duo Pianism", explore the artistic significance and performance practice of two-piano compositions. In addition to performance guides, several references make a comparison between solo programs and piano duo works. A comparative study can be found in 1986 in Chikako Sloan's article, which illustrates the differences of the rehearsal approach, technical aspects, and artistry between duo-piano performance and solo-piano performance [11].

\section{STYLISTIC FEATURES AND COMPOSITIONAL INTENT}

As the genre of piano ensemble works has more formats than piano duet and piano duo, a good understanding of piano-ensemble works for teamwork pianists leads to the appropriate interpretation of piano ensemble performance. To make an insightful investigation of the piano ensemble playing, the change of instrumental development, social influence, and composers' cultural background should be studied as well. The following paragraph will provide the stylistic features and compositional intent of various pianoensemble arrangements for each period.

\subsection{Renaissance Era}

Throughout the sixteenth century, a massive quantity of vocal music was prominent because of the popularity of sacred and secular music including masses, motets, madrigals, and chansons. Therefore, the instrumental playing was strongly associated with vocal music during this time, notably appearing in the liturgical ceremony of churches as prelude or interlude, except for few chapels like the Sistine Chapel in Rome which remained unaccompanied choirs. Although instrumental music seemed to be secondary important in the renaissance period, purely keyboard music had already existed in tablature arrangement. The virginal and the spinet are both precursor versions of keyboard instruments at the renaissance era, which appeared with limited sound range and less sonority due to the lighter construction and the plucking mechanism. Historically, the keyboard instrument became more independent and widely used when the English keyboard composers built up the school of "English virginalists" in the late 16th century, at the time the keyboard intabulations displays the embellished style of music [12]. The most famous manuscript collection of the keyboard in this period was "Fitzwilliam Virginal Book", which contains almost three-hundred folk songs and dance tunes in variation form [13]. Although the keyboard instrument's structure in the renaissance did not have the best facility for multiple players to perform together, there were several keyboard ensemble compositions written down. In 1976, the Schirmer publisher released a collection of five four-hand music from England, Spain, Italy, France, and Germany, composed anonymously during the renaissance. Observing the scores and the front page of this collection, these pieces were 
written for two virginals in dance-like music style. It was very likely that these works were composed for dance's social activity as the dance music of the renaissance was often improvised and casually written out without attribution to a particular composer [14].

\subsection{Baroque Era}

In the Baroque period, instrumental music began to flourish, and composers started to explore keyboard instruments' potentiality. It is believed that John Bull composed the earliest documented piano ensemble piece (1562-1628), titled "A battle, and No battle" for two players playing three hands together on one virginal. Meanwhile, another two composers Nikolas Carleton (1570-1630) and Thomas Tomkins (1572-1656), collaboratively composed the pieces "A Verse for Two to Play on One Virginal or Organ" and "A Fantasy for Two to Play", which remain the oldest manuscripts of piano ensemble music to the present [15]. Giles Farnaby's (1563-1640) composition "For Two Virginals" expands to two keyboards for two players and stands as the earliest notion of keyboard duo music. Later on, French composers such as Gaspar Le Roux (d. 1707) and François Couperin (1668-1733) wrote three-staves compositions for harpsichord with the bottom line labeled in Roman numerals for improvisations. As the range of the harpsichord possessed only four or four and a half octaves at the time, piano ensemble playing was less cultivated. Generally, most keyboard ensemble compositions during the Baroque era were experimental works that were easily neglected because of the instrumental restrictions.

\subsection{Classical Era}

Debates on which four-hand piece was first published or printed remains controversial. However, Charles Burney's (1726-1841) "Four Sonatas or Duet for Two Performers on one Pianoforte or Harpsichord" published in 1777 first documented the value and techniques concerning the four-hand playing. Accordingly, Burney's annotation elevated the importance of piano duet music in instrumental literature. Subsequently, the keyboard ensemble works gradually turned into a higher art form since J.C. Bach published his two duets for harpsichord in 1778 and influenced the following composers such as Mozart and Clementi [16]. Margaret MacCathy's article "Two Piano Music around Beethoven's Time: Its Significance for the College Teacher" discusses the two-piano music between 1770 and 1830. MacCathy's discovery compared Mozart with his peers and found that Mozart had most piano duet compositions, particularly in his early composing stage. For example, his compositions KV19d, KV381, KV358 were all four-hand compositions for the harpsichord. Besides, Mozart and his sister, Maria Anna Nannerl's London performance of J.C. Bach's duet in 1765 has been considered the first public concert of keyboard ensemble playing [17]. During the same period, the keyboard instruments reached a wider range of five to six octaves of keys and allowed more than a single player to perform together on one piano. As a result, classical composers such as Muzio Clementi (1752-1832), Jan Ladislav Dussek (1760-1812), and John Baptist Cramer (1771-1858) all wrote piano duets. The classical composers' request for keyboard instruments influenced piano manufacture. In 1794, the Broadwood Company produced a piano with six and a half octaves, which was also called a "duet range keyboard". In 1850, the keyboard's tonal range expanded to the length of eighty-eight keys as seen in the modern piano. According to the scholar Alexander Weinmann, the total amount of piano duet music between 1760 and 1860 were equivalent to the piano solo works. Accordingly, the importance of piano duet was elevated to a greater extent in the classical era [18].

\subsection{Romantic Era}

Piano music became a mainstream of entertainment in daily life during the nineteenth century for several reasons. First, the rise of the middle class and the sustainable development of the piano factory increased the staggering quantity of piano duet works. Significantly, the invention of the repetition mechanism known as the double escapement, iron frame, and sustaining pedal made composers seek more variety of pianism. In order to reinforce the expressions and virtuosity of piano, composers wrote piano ensemble music with much more advanced pianistic techniques. Moreover, the culture of salon music and the promotion of parlor concert events were so prevalent that piano ensemble performance created a social occasion for the intimate and enjoyable communication between friends and acquaintances. Chronologically, composers including Carl Maria von Weber (17861826), Franz Schubert (1797-1828), Felix Mendelsshon (1809-1847), Robert Schumann (1810-1856), Johannes Brahms (1833-1897), Antonín Leopold Dvořák (1841-1904), Edvard 
Grieg (1843-1907), and Max Reger (1873-1916) all wrote piano duets for pianists. The ensemble performance coordination spanned from piano duet to piano duo, which presented two grand pianos tail by tail with a much more sonorous effect that was more suitable for a concert performance on a bigger stage. The well-known original two-piano music for concert program contains Frederic Chopin's (18101849) "Rondo in C major for two pianos", CharlesCamille Saint-Saëns's (1835-1921) "Caprice Arabe, Op.96" and "Scherzo Op.87", Sergei Rachmaninoff's (1873-1943) "Suite for two pianos, No.1, No.2", and Darius Milhaud's (1892-1974) "Scaramouche". In addition to the original twopiano repertoire, some of the piano duo pieces in the nineteenth century were transcribed from the symphonic and solo piano works, or even vice versa. The piano transcription initiated from the late nineteenth century and became even more popular in the romantic period. Many orchestral or instrumental works can be transcribed to the piano setting for a new perception to the audience. For instance, part of Edvard Grieg's first symphony (1863-1864) was transcribed by the composer to a piano reduction in 1875 with the new title, "Two Symphonic Pieces, Op.14". Moreover, Johannes Brahms has both piano four-hand and piano solo versions of his composition "Sixteen Waltzes, Op.39", respectively published in 1865 and 1866. Composers not only transcribed their own music but also made transcriptions of pre-existing works by predecessors. In 1922, Ferruccio Busoni (18661924) transcribed Mozart's organ piece "Fantasia in F minor, K.608" for piano duo. The French composer Ernest Guiraud (1837-1892) transcribed Saint-Saëns's "Danse Macabre, Op.40" and George Bizet's "Carmen" for piano duos. As the live hearing experience of a symphonic concert or an opera performance was viewed as luxury behavior in the nineteenth century, piano transcriptions provided a chance for the audience with a limited financial resource to appreciate more types of music [19]. Overall, the diverse source of transcriptions for piano duet and piano duo implies the accessibility of piano as a principal instrument that served as a compositional tool and a medium for the public to learn the music in the nineteenth century.

\subsection{Contemporary Era}

From the twentieth century toward the present day, more piano ensemble compositions were created for displaying innovative compositional techniques and distinctive timbre. In addition to adopting the musical legacy from romanticism, contemporary composers further enhance the artwork's revolutionary musical effect with avantgarde aesthetic values. The utilization of the blurring sound, polyrhythm, bitonality, meter and tempo changes, and new notation system makes the ensemble collaboration more challenging. Compared with the traditional presentation of a piano duet and piano duo, the context of ensemble music for multiple pianists in the performance accentuates the partnership and communicative ability to a higher degree. Meanwhile, the definition of piano ensemble playing expands to a team-work that requires more pianists to participate in one composition. The contemporary composer Walden Hughes (1955-2019) made the twelve-hand arrangement for the piano duo on Johann Strauss's (1825-1899) "Radetzky March", which is intended to be played by six pianists in total, three on each piano. The Russian composer Vladislav Uspensky (1937-2004) composed a piano ensemble piece for six hands by two pianists playing together on the first piano and another pianist on the second piano. In the modern days, the significance of piano ensemble performance has also been improved as several important international music competitions began to add a piano-duo category recently. The ARD international piano duo competition and Maria Canals international music competition are notable competitions providing new career opportunities for team-work pianists.

\section{FORMATS AND FEATURES OF PIANO ENSEMBLE}

Historically, piano ensemble format started with a smaller group of players due to the limitation of instrument and the uncommon knowledge in ensemble work. To trace back the origin of piano ensemble history, one can discover a noticeable stylistic change of musical concept as well as compositional purpose.

\subsection{Piano Ensemble for Three Hands}

A Piano work for three hands was originally written for two players to assimilate to the keyboard's narrow structure. Two keyboardists performed the composition for three hands, with one of them playing only by a single hand. Although this presentation is more historical and rarely seen in modern piano ensemble music, it was still observable in the nineteenth and twentieth centuries. For example, the renowned educator in the nineteenth century, Ferdinand Beyer (1803- 
1863), wrote piano etudes for three hands in his collection of studies, Op.101 for ensemble performance training. The publication of Byer's Op.101 was published in 1850 at the time the construction of the piano has reached eighty-eight keys, and understandably Byer's writing was significantly influenced by his pedagogical idea rather than the instrumental restrictions. Remarkably, the contemporary composer Bohuslav Martinů (1890-1959) composed a piece for two pianists with three hands, called "Avec un doigt for piano three-hand, H185". The whole first part of this work is assigned to be played by only one finger.

\subsection{Piano Ensemble for Four Hands}

The piano duet's musical structure came from the difficulty of the hand crossing technique in a broader range on the harpsichord [20]. In the most concrete sense, four-hand piano music opens up the possibility of carrying out the large-scaled and expanding texture in piano musical writings appropriate for a group of people to perform. The four-hand music became formal with the majority of the publication in the seventeenth century, at the time the style of living and society altered, and the leisure activity of concert was more affordable to most people [21]. Nowadays, four-hand music's performance convention seems continuously evergrowing and distributing for its substantive value and positive outcome. The duet playing between students and teachers also creates pedagogical modeling beneficial to the music education for learning and listening experience.

\subsection{Piano Ensemble for Six Hands}

Typical six-hand piano music is composed for three pianists at one piano. Compared with the piano duet, piano music for six hands has a more distinctive sound that displays the full range of a modern piano's sonority. The pianistic sources featuring the six hands usually are created for the striking force of employing an additional one player in the team group. Rare pieces are original works for six-hand music, but contemporary composers have adopted the arrangement of a piano ensemble for six hands for modern performance. The famous examples include Sergei Rachmaninoff's "Romance and Valse", and Alfred Schnittke's "Hommage".

\subsection{Piano Ensemble for Eight Hands}

The piano ensemble for eight hands can be categorized into two types. One is how four pianists play on the same piano. The other is performed by two pianos with two pianists sharing one piano simultaneously, developed from a piano duo format. Much piano eight-hand music is transcribed from more extensive chamber music or symphonic work with the complexity of texture found in masterpieces. Eight-hand transcriptions of orchestral works usually command the pianistic virtuosity in affinity with the theatrical and spectacular effect of the original setting for the auditorium. A handful of piano eight-hand music for two pianos has emerged from the late nineteenth century to the present in such pieces as seen by Virginia Speiden Carpe's (1908-2005) arrangement on Edgar Elgar's (1857-1934) "Pomp and Circumstances, Op.39", and Albert Lavigna's (1846-1916) "Galop Marche".

\subsection{Piano Ensemble for Twelve Hands}

Based on a piano duo format, piano twelvehand music was expanded from the piano ensemble for six hands by three pianists playing on each piano, and six pianists playing at two pianos for the same music simultaneously. The development of piano twelve-hand music was contributed particularly to the piano ensemble group. The 19century composer Giovanni Battista Pagnoncelli (1835-1906) wrote an original work for piano twelve hands with the piece title, "Ballata e Bizzarrita". More recently, the Australian American composer Percy Grainger (1882-1961) composed a piece called "English Dance" for six hands on two pianos in 1924. The Russian composer Vyacheslav Gryaznov (1982s) also made a transcription for piano twelve hands on Mozart's "Turkish March" and M. Glinka's (1804-1857) opera "Luslan and Lumilla".

\subsection{Piano Ensemble for Sixteen Hands}

Inevitably, the formation of piano ensemble groups is constantly growing as increasing awareness of piano ensemble music becomes obvious in recent years. The rise of ensemble music in concert activities results in a certain audience amount regularly in support of piano ensemble performance. Hence, more and more commissioned works are assigned for multiple pianists in a teamwork group to interpret the ensemble music collaboratively. Current existing music for piano 
sixteen hands includes A. Yossifov (1940-2016)'s "Toccata", Canonica Paolo's (1846-1902) "Polka Concertata, Op.190", and many other repertoires. Furthermore, the contemporary notation and piano techniques such as tone cluster, indeterminate boundary notes, prepared piano, plucking and striking, the addition of human sound, and silentlydepresses notes are often exploited in the piano ensemble music for multiple pianists.

\section{PEDAGOGICAL STRATEGIES FOR PIANO ENSEMBLE PERFORMANCE}

The pedagogical strategies for piano ensemble performance involve breathing, signaling, watching, listening, and even social skills besides the basic performing techniques as demanding as solo piano performance [22]. In a broader sense, piano ensemble collaboration also relies on an interpersonal relationship through musical and verbal communications. A good partnership establishes a consensus of musical taste and the similar artistic perspectives of co-workers are very determinable as well. Good experience of ensemble playing makes the music performance as if it was accomplished by one player. Despite the difficulties in building up a smooth path for different pianists of various cultural backgrounds to meet a high standard of collaboration, the tacit knowledge and pleasant collaborative experience did occur as long as each pianist keeps sensitive and attentive to others during the cooperation. From the sociological perspective, piano ensemble learning displays a reflection of a small community sharing one surrounding environment in which the psychosocial factors influence the artistic outcome. Interestingly, the pedagogical strategies for the ensemble playing are very different from the piano solo lesson, which most roots in cultivating the soloists' capability. On the contrary, the piano ensemble's pedagogical strategies are more like an experimental process by which the participants feel the pacing and flowing of music together, and sometimes with additional discussion of musical insight for specific works. The discussion below will explore four aspects of gesture, balance, pedaling, and phrasing issues in ensemble works.

\subsection{Seated Position and Playing Gesture}

In the piano ensemble performance, the seated position and body gesture are important issues regarding the interactions between performers. For some pieces in which the different parts of music have overlapping registers on the piano, the pianists need to sit relatively close to each other with middle-hand interchanges as sometimes the same note is played right after the another by different performers [23]. Considering the variable performing habits of each individual's playing motion, the height of the seat, and how to juxtapose the piano benches are also an essential part of the experiment during the rehearsals. Moreover, collaborative pianists need to accommodate uncomfortable positions in a group and think about the fingering with the synchronized standpoint to fit the physical proximity of ensemble playing. The motion of page-turning should also be as less interrupting as possible in the musical performance. Meanwhile, the coordination between the teamwork pianists has to be accomplished naturally without excessive consciousness.

\subsection{Balance}

A well-integrated sound is desirable in a piano ensemble performance, which implies an equal tonal balance between partners without any particular sound overshadowed by other voices. Besides, the sonorous balance need to be so subtle that all pianists are equally important and devoted. In some exceptional cases when the music text illustrates a solo-accompaniment context like a piano reduction of a concerto, the first piano mostly plays the leading role in the entire performance. However, the transition between different piano parts and the integration of sound from pianos should be fluent and spontaneous. Although the interpretation and pedagogical strategies for piano ensemble playing are varied from person to person and from occasion to occasion, an essential framework of the rehearsal process is widely accepted. In common practice, when two pianos were placed tail by tail, one piano's lid has to be removed for a more balanced resonance [24]. However, the adjustable balance of piano ensemble playing is also mandatory depending on the compositional intent and the artistic pursuit of the compositions. In most original ensemble music for multiple pianists, the melodic lines and thematic layering are usually switchable and ever-changing. Thus, attentive listening skill is highly demanding from the pianists.

\subsection{Pedaling}

The application of pedaling in piano ensemble playing should take into account the sonority of the historical keyboard instruments in the original 
version of music. The pedaling changes are often utilized to follow the harmonic progression and to shape the primary melodies in the musical structure. As each part of the piano- ensemble has a distinctive voice, the performers have to use the pedals for taking care of the overall structure of context. Generally, the one who controls the pedal needs to be aware of other voices besides his own part of music, and the necessary adjustment of pedaling always occurs on the stage in accord with the uncertainty in the process of performance. Furthermore, the acoustic aesthetics as well as the placement of pianos in performance should also be considered when practicing how to pedal in the ensemble performance for a proper musical pursuit.

\subsection{Phrasing}

The musical interpretation in the piano ensemble is strongly in affinity with the team-work pianists' mutual comprehension of phrasing and rhythmic pulse, which altogether reveal interesting collaborative musical philosophies. Particularly, the issue of how to shape the phrases is the most frequently discussed topic in the examination of piano ensemble performance. Interactive partnership in ensemble playing creates a dialogic relationship between various musical phrases in a sense the viability of artistic views is expressed. Moreover, the phrasing dynamics range in a chamber music context raises a holistic view of the physical aspects, including hand, arm, and torso movements. A direction of the phrasing embodies the overall ideas of compositions. As a result, the interpretation of phrasing significantly influences the playing experience on many levels.

\section{CONCLUSION}

Piano ensemble works have significance in both cultural evolution and collaborative artistry. The study of piano ensemble repertoire inspires the modern teaching practice of piano lessons and offers an interesting view of piano playing. The collaborative skills required in piano ensemble work create a more communicative teaching method in music education. To develop the ensemble playing skill, the coordinative ability and adaptability to wide range of possible changes on the stage should be emphasized in the training process. The interpretation and pedagogical strategies for piano ensemble playing can be progressed from accumulated experience. Therefore, the scope of piano ensemble playing enlarges the instrumental performance and music learning's modern perspectives, and it symbolizes a new genre of artwork. It is hoped that this study will inspire more in-depth investigations on the development and application of more various piano ensemble compositions.

\section{AUTHORS' CONTRIBUTIONS}

This paper is independently completed by KuoYing Lee.

\section{REFERENCES}

[1] Yunn Bing Christine Tan, Teaching Intermediate-level Technical and Musical Skills through the Study and Performance of Selected Piano Duos, DMA Thesis, West Virginia University, 2007.

[2] James Friskin, Irwin Freundlich, Music for Piano: A Handbook of Concert and Teaching Material from 1580 to 1952, New York, Dover Publication Inc., 1973.

[3] Gary Keith McRobert, An Annotated Catalog of Original Two-Piano Literature 1950-1970, M.A. Thesis, California State University at Long Beach, 1973.

[4] Eulalie Wilson Jeter, The Study, Analysis and Performance of Selected Original Two-piano Music of Contemporary American Composers, Ed.D. Dissertation, Columbia University, 1978.

[5] Frederic Ming Chang, Albert Faurot, Team Piano Repertoire: A Manual of Music for Multiple Players at One or More Pianos. New Jersey: The Scarecrow Inc, 1976.

[6] Carolyn Maxwell, Maxwell Music Evaluation: Notebook Ensemble Piano Literature. Colorado, Maxwell Music Evaluation, 1983.

[7] Howard Ferguson, Keyboard Duets from the 16th to the 20th Century for One and Two Pianos: An Introduction, New York: Oxford University Press, 1995.

[8] William Crandall Leech, Music for Two Pianos, M.M. thesis, University of Kansas, 1941.

[9] Pauline Venable Turrill, The Two-Piano Idiom: An Analysis and Evaluation, M.A. Thesis, University of California, 1951. 
[10] Dorotht Bridenthal, A Critical Evaluation of Two-piano Music Available in American Publication, M.M. Thesis, University of North Texas, 1945.

[11] Chikako Sloan, Comparison of Duo-piano Performance and Solo-piano Performance, M.M. Thesis, The Ball State University, 1986.

[12] Howard Mayer Brown, "Embellishment in early sixteenth-century Italian intabulations," in Proceedings of the Royal Musical Association, Oxfordshire, vol.100, Taylor \& Francis, Ltd., pp.49-83, 1973-1974.

[13] "The Fitzwilliam virginal book," The Musical Times and Singing Class Circular, London, vol. 41, no. 684, pp. 90-92, 1900. DOI: https://10.2307/3367137

[14] Norma Verilli Iadone, Five Renaissance Pieces for Piano, Four Hands, New York, Schirmer, 1976.

[15] Frank Dawes, "Nicholas Carlton and the earliest keyboard duet," The Musical Times, London, vol. 92, no. 1306, pp. 542-546, 1951. DOI: https://doi.org/10.2307/934079

[16] Cameron McGraw, Piano Duet Repertoire: Music Originally Written for One Piano, Four Hands. Bloomington: Indian University Press, 1981.

[17] Margaret W. McCarthy, "Two-piano music around Beethoven's time: its significance for the college teacher," College Music Symposium, MT, vol. 17, no.2, pp.131-143, 1977.

DOI:https://www.jstor.org/stable/40373897

[18] Gisela Waldtraut Scriba, The Piano Duet as Teaching Medium: An Overview and Selective Syllabus For The Beginner Pianist, M.M. thesis, University of Pretoria, 2010.

[19] William Weber, Music and the Middle Class: The Social Structure of Concert Life in London, Paris and Vienna. New York: Holmes and Meier, 1975.

[20] Walden Hughes, "Music for multiple pianos during the past 400 years," Clavier, IL, vol. 42, no.5, pp. 21-25, 2003.

[21] Pierson A. Wetzel, The Pedagogical Benefits of Duet Playing: A Vannetelbosch Companion, D.M.A. Dissertation, The Ohio State University, 2007.
[22] Anna Grinberg, Touch Divided: Artistic Research in Duo Performance, Ph.D. Thesis, The University of Queensland, 2016.

[23] Cecilia Oinas, "From four-handed monster to all-embracing VISHNU: the case of "middle hands" within a piano four hands duo," Music \& Practice, Oslo, vol.5, pp.1-19, 2019. DOI: https://doi.org/10.32063/0511

[24] Hans Moldenhauer, Duo-Pianism. Chicago: Chicago Musical College Press, 1950. 